\title{
Three novel circRNAs upregulated in tissue and plasma from hepatocellular carcinoma patients and their regulatory network
}

\author{
Lianghai Wang $^{*+}$ (D), Lisha Zhou ${ }^{\dagger}$, Jun Hou, Jin Meng, Ke Lin, Xiangwei Wu* and Xueling Chen ${ }^{*}$
}

\begin{abstract}
Background: The regulatory roles of circular RNAs (circRNAs) in tumorigenesis have attracted increasing attention. However, novel circRNAs with the potential to be used as serum/plasma biomarkers and their regulatory mechanism in the pathogenesis of hepatocellular carcinoma (HCC) remain explored.

Methods: CircRNA expression profiles of tumor tissues and plasma samples from HCC patients were compiled and jointly analyzed. CircRNA-miRNA-mRNA interactions were predicted by bioinformatics tools. The expression of interacting miRNAs and mRNA was verified in independent datasets. Survival analysis and pathway enrichment analysis were conducted on hub genes.

Results: We identified three significantly up-regulated circRNAs (hsa_circ_0009910, hsa_circ_0049783, and hsa_ circ_0089172) both in HCC tissues and plasma samples. Two of them were validated to be indeed circular and could be excreted from hepatoma cells. We further revealed four miRNAs (hsa-miR-455-5p, hsa-miR-615-3p, hsa-miR-18a-3p, hsa-miR-4524a-3p) that targeting circRNAs and expressed in human HCC samples, and 95 mRNAs targeted by miRNAs and significantly up-regulated in two HCC cohorts. A protein-protein interaction network revealed 19 hub genes, 12 of them (MCM6, CCNB1, CDC20, NDC80, ZWINT, ASPM, CENPU, MCM3, MCM5, ECT2, CDC7, and DLGAP5) were associated with reduced survival in two HCC cohorts. KEGG, Reactome, and Wikipathway enrichment analysis indicated that the hub genes mainly functioned in DNA replication and cell cycle.
\end{abstract}

Conclusions: Our study uncovers three novel deregulated circRNAs in tumor and plasma from HCC patients and provides an insight into the pathogenesis from the circRNA-miRNA-mRNA regulatory network.

Keywords: Liver cancer, ceRNA, Biomarker, Prognosis

\section{Background}

Hepatocellular carcinoma (HCC) accounts for approximately $90 \%$ of primary liver cancer, the sixth most commonly diagnosed tumor and the fourth leading cause of cancer-related death worldwide [1]. Due to the early

\footnotetext{
*Correspondence: Ih_wang@shzu.edu.cn;wxwshz@126.com; chenxueling@shzu.edu.cn

${ }^{\dagger}$ Lianghai Wang and Lisha Zhou contributed equally to this work Key Laboratory of Xinjiang Endemic and Ethnic Diseases/the First Affiliated Hospital, Shihezi University School of Medicine, Shihezi, Xinjiang, China
}

asymptomatic, most $\mathrm{HCC}$ patients are diagnosed at advanced stages with metastasis, thus losing the opportunity for radical resection [2,3]. With the improvement of diagnosis and treatment technologies, the survival of HCC patients has increased. However, the 5-year survival rate is only $18 \%$ as high frequencies of tumor metastasis and recurrence [1]. To improve patients' survival and quality of life, it is urgent to explore novel biomarkers for early diagnosis, prognosis, and treatment of liver cancer $[2,4,5]$.

Circular RNA (circRNA) is a type of stable transcripts that do not have a free $5^{\prime}$ end cap and $3^{\prime}$ end poly (A) tail the original author(s) and the source, provide a link to the Creative Commons licence, and indicate if changes were made. The images or other third party material in this article are included in the article's Creative Commons licence, unless indicated otherwise in a credit line to the material. If material is not included in the article's Creative Commons licence and your intended use is not permitted by statutory regulation or exceeds the permitted use, you will need to obtain permission directly from the copyright holder. To view a copy of this licence, visit http://creativecommons.org/licenses/by/4.0/. The Creative Commons Public Domain Dedication waiver (http://creativeco mmons.org/publicdomain/zero/1.0/) applies to the data made available in this article, unless otherwise stated in a credit line to the data. 
and forms a circular structure by covalent bonds $[6,7]$. CircRNA was initially considered to be a by-product of splicing. Nevertheless, with the advancement of highthroughput sequencing technology and bioinformatics analysis, the cellular functions and potential biomedical applications of circRNAs become a new research hotspot [8]. CircRNAs are abundant in the cytoplasm of eukaryotic cells and cell-type specific [9-11]. Recent studies have shown that circRNAs are essential to modulate gene expression in the nucleus, act as decoys for miRNAs and proteins, and serve as templates for translation [3, 1215]. The regulatory roles of circRNAs in tumorigenesis have also attracted more attention [5, 16, 17]. Increasing studies suggest that circRNAs play essential roles in the occurrence and development of HCC, and are expected to have the potential to become diagnostic biomarkers and therapeutic targest [18, 19]. However, novel circRNAs with the potential to be used as serum/plasma biomarkers and their regulatory mechanism in liver cancer pathogenesis remain to be explored.

In this study, we jointly analyzed three HCC tissuesrelated microarray datasets from the Gene Expression Omnibus (GEO). Such a relatively large sample size allows for higher statistical power in the identification of differentially expressed circRNAs. CircRNAs that were also increased in HCC plasma were obtained by overlapping with an HCC plasma samples-related microarray dataset. Subsequently, a circRNA-miRNA-mRNA network was constructed to provide an insight into the potential pathogenesis of the identified circRNAs in HCC. The flow chart recapitulating the present work is shown in Fig. 1.

\section{Methods}

CircRNA expression processing of $\mathrm{HCC}$ microarray datasets

The four publicly available HCC-related circRNA microarray datasets used in this study were downloaded from the GEO database, including three gene expression profiles on platform GPL19978 and one from the platform GPL26925. Data normalization and combination were performed by pooling the three datasets of the GPL19978 platform using the Bioconductor Limma package. The principal component analysis was performed to ensure a minimal batch effect in the meta-cohort. Then, differential analysis of the pooled expression data was also conducted by Limma with the criteria of $\mid \log 2$ (foldchange) $\geq 0.585$ and $P$-value $<0.05$. Subsequently, the processed plasma circRNA data of GSE135806 based on the thresholds of $\mid \log 2$ (foldchange) $\mid \geq 1$ and $P$-value $<0.05$ was downloaded from the GEO, and further intersected with the differentially expressed circRNAs in HCC tissues with an online tool (http://bioinformatics.psb.ugent.be/ webtools/Venn/).

\section{Cells and cell culture}

Human HCC cell lines HepG2, Huh7, and Hep3B were purchased from the Cell Bank of Shanghai Institutes for Biological Sciences, Chinese Academy of Sciences. Cells were cultured in Dulbecco's modified Eagle's medium (DMEM; Gibco) supplemented with $10 \%$ fetal bovine serum (Gibco) and $1 \%$ penicillin/streptomycin at $37^{\circ} \mathrm{C}$ in a humidified $5 \% \mathrm{CO}_{2}$ incubator.

\section{CircRNA validation}

The culture medium of hepatoma cells was collected, centrifuged at $1,000 \mathrm{~g}$ for $10 \mathrm{~min}$ and $14,000 \mathrm{~g}$ for $2 \mathrm{~min}$ to remove cells and debris [20]. Total RNA from cells or culture medium was extracted using Total RNA Kit I (OMEGA) or TRIzol LS Reagent (Invitrogen) according to the manufacturer's instructions. cDNA was synthesized from total RNA treated with or without RNase R exonuclease (Geneseed) for real-time PCR on a CFX96 system (Bio-Rad). PCR products were further visualized by agarose gel electrophoresis. $\beta$-actin was used as an endogenous control. Primer sequences were shown in Table 1.

\section{Prediction of miRNA binding and miRNA target genes}

The Cancer-specific circRNAs database (CSCD) [21] and circbank (http://www.circbank.cn/index.html) were used to predict miRNA response elements (MRE or binding sites). Overlapped miRNAs in the two databases were considered as potential target miRNAs of circRNAs. The expression of the candidate miRNAs was further verified base on the miRNA-seq dataset GSE76903 [22]. The miRNA-mRNA interactions were predicted with miRWalk [23], with only the results from binding to $3^{\prime}$ UTR filtered.

\section{Collection of differently expressed genes in HCC}

RNA-Seq data of the TCGA-LIHC project consisting of 374 liver cancers and 50 normal tissues were downloaded from the GDC Data Portal. The DESeq2 package was used to screen differentially expressed genes with thresholds of $\mid \log 2$ (fold change) $\mid \geq 1$ and $P$-value $<0.01$. With the same filter criteria, differently expressed genes from expression profiling by an array (GSE14520, GPL3921 Affymetrix HT Human Genome U133A Array) containing 225 HBV-related HCC and 220 non-tumor tissues were also determined.

\section{Establishment of circRNA-miRNA-mRNA network and identification of hub genes}

A circRNA-miRNA-mRNA regulatory network was established by integrating the circRNA-miRNA and miRNA-mRNA interactions and visualized using the 


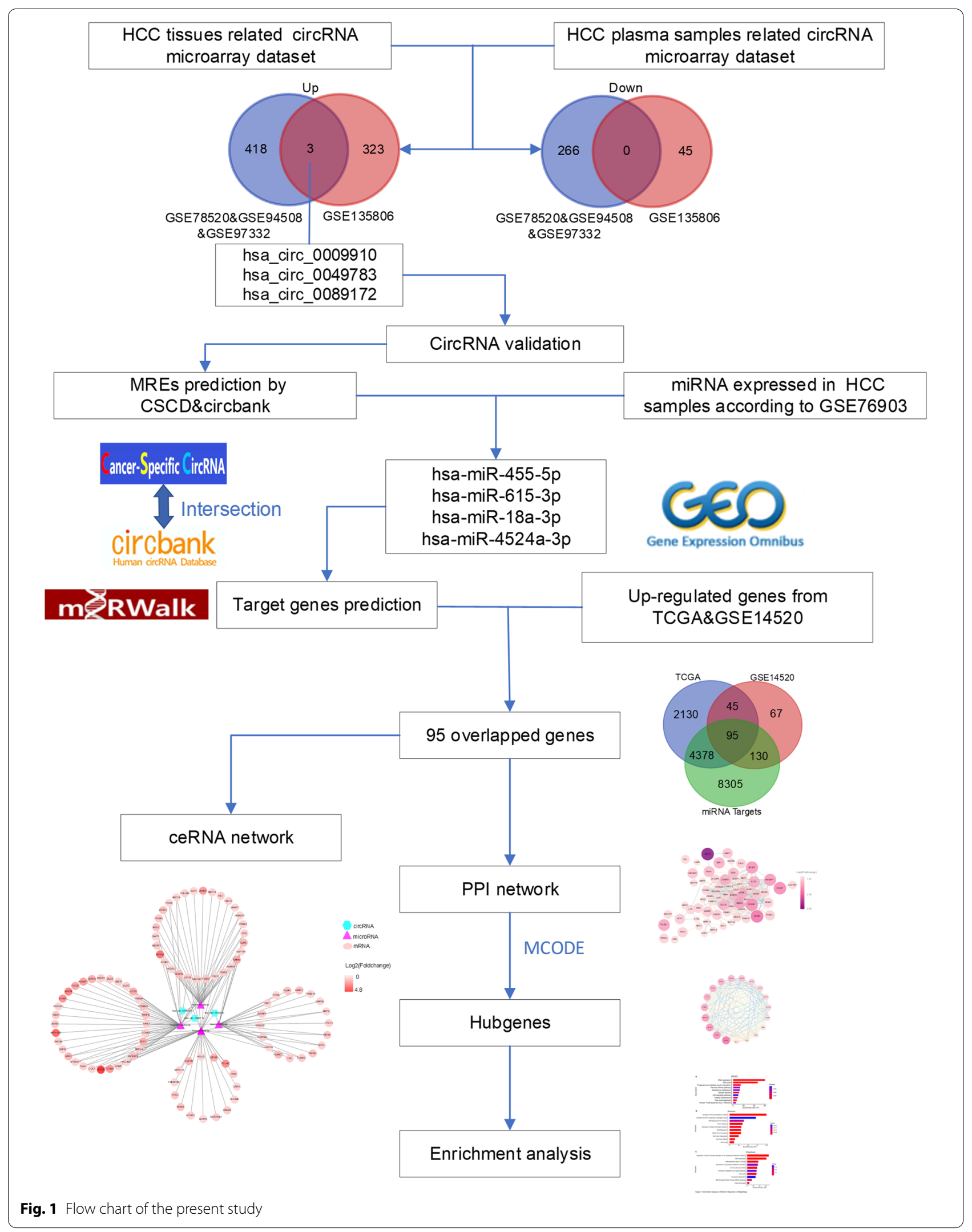


Table 1 Primer sequences for real-time PCR

\begin{tabular}{lll}
\hline Gene & Forward primer & Reverse primer \\
\hline $\begin{array}{l}\text { hsa_circ_0009910 } \\
\text { (divergent) }\end{array}$ & GTGAGAGGCATCAGTGAGGT \\
$\begin{array}{l}\text { hsa_circ_0009910 } \\
\text { (convergent) }\end{array}$ & GGACCCCGTTACCACAGAAG \\
$\begin{array}{l}\text { hsa_circ_0089172 } \\
\text { (divergent) }\end{array}$ & AAGAATAACCCTGCAACCCCTT \\
$\begin{array}{l}\text { hsa_circ_0089172 } \\
\text { (convergent) }\end{array}$ & GCCTGTCTCGATCAGCCTTT & CCACTTTCATGTGCCTCCGA \\
\begin{tabular}{l}
-actin \\
\hline
\end{tabular} & GAGAAATCTGGCACCACACC & GACAGATGACGTTGAGCTGACT \\
\hline
\end{tabular}

Cytoscape 3.7.2 software [24]. The candidate mRNAs were imported to the STRING database (https://strin g-db.org), and protein-protein interaction (PPI) network was created. Then, MCODE, a clustering algorithm that detects densely connected regions in large protein interaction networks [25], in Cytoscape was used to identify hub genes in the PPI network. The highest-scoring nodes recognized as hub genes are listed in Table 2.

\section{Survival analysis of hub genes}

Survival data of patients from TCGA-LIHC and patients from GSE14520 were obtained from UCSC
Xena (https://xenabrowser.net/) and GEO. Patients were divided into two groups based on the median expression values for TCGA-LIHC and based on the minimum $P$-value cut off values for GSE14520. The Kaplan-Meier's survival curves for the hub genes were visualized using GraphPad Prism.

\section{Functional enrichment analysis of hub genes}

KEGG, Reactome, and Wiki pathway enrichment analysis of the 12 hub genes were carried out using Webgestalt online tool (http://www.webgestalt.org/). A $P$-value of less than 0.05 was set as the cut-off criterion.

Table 2 Basic information of 19 significantly up-regulated hub genes in TCGA-LIHC and GSE14520-GPL3921

\begin{tabular}{|c|c|c|c|c|c|}
\hline \multirow[t]{2}{*}{ Hub genes } & \multirow[t]{2}{*}{ MCODE Score } & \multicolumn{2}{|c|}{ Log2(Fold Change) } & \multicolumn{2}{|c|}{ Log-rank $P$ value of overall survival } \\
\hline & & TCGA-LIHC & GSE14520 & TCGA-LIHC & GSE14520 \\
\hline NUSAP1 & 16.50292398 & 1.60 & 2.37 & $0.0081^{* *}$ & 0.1060 \\
\hline CCNA2 & 16.50292398 & 1.08 & 1.28 & $0.0012^{* *}$ & 0.0514 \\
\hline MCM6 & 16.50292398 & 1.01 & 2.02 & $0.0003^{* * *}$ & $0.0124^{*}$ \\
\hline CCNB1 & 16.50292398 & 1.00 & 2.49 & $0.0001^{* * *}$ & $0.0021^{* *}$ \\
\hline CDC20 & 16.50292398 & 1.58 & 1.90 & $<0.0001^{* * * *}$ & $0.0459^{*}$ \\
\hline BUB1B & 16.50292398 & 4.74 & 1.71 & $0.0032^{* *}$ & 0.0666 \\
\hline NDC80 & 16.50292398 & 4.46 & 1.31 & $0.0025^{* *}$ & $0.0444^{*}$ \\
\hline ZWINT & 16.50292398 & 1.14 & 2.43 & $<0.0001^{* * * *}$ & $0.0056^{* *}$ \\
\hline ASPM & 16.50292398 & 1.02 & 3.01 & $0.0172^{*}$ & $0.0014^{* *}$ \\
\hline CENPU & 15.58169935 & 1.81 & 1.96 & $0.0020^{* *}$ & $0.0113^{*}$ \\
\hline FANCI & 15.58169935 & 2.21 & 1.19 & $0.0132^{*}$ & 0.1117 \\
\hline GMNN & 15.58169935 & 1.57 & 2.13 & 0.3349 & $0.0195^{*}$ \\
\hline HELLS & 15.58169935 & 2.58 & 1.05 & $0.0204^{*}$ & 0.0554 \\
\hline MCM3 & 15.58169935 & 1.95 & 1.48 & $0.0261^{*}$ & $0.0333^{*}$ \\
\hline MCM5 & 15.58169935 & 2.10 & 1.38 & $0.0039^{* *}$ & $0.0015^{* *}$ \\
\hline ECT2 & 15.58169935 & 4.73 & 2.03 & $0.0050^{* *}$ & $0.0254^{*}$ \\
\hline CDC7 & 15.58169935 & 3.75 & 1.09 & $0.0002^{* * *}$ & $0.0357^{*}$ \\
\hline RRM1 & 15.58169935 & 1.24 & 1.12 & $0.0294^{*}$ & 0.0613 \\
\hline DLGAP5 & 15.58169935 & 3.32 & 1.31 & $0.0003^{* * *}$ & $0.0320^{*}$ \\
\hline
\end{tabular}




\section{(See figure on next page.)}

Fig. 2 Identification of three up-regulated circRNAs in HCC tissues and plasma samples. a, b PCA plot of the first two components before (left) and after (right) Limma standardization, which minimizes the batch effect. $\mathbf{c}$ Heatmap for ten selected differentially expressed circRNAs in the pooled 15 pairs of HCC samples. $\mathbf{d}$ Venn diagram of up-regulated and down-regulated circRNAs in the HCC tissues-related meta-cohort (GSE78520\&GSE94508\&GSE97332) and the HCC plasma samples-related microarray dataset (GSE135806). e Volcano plot showing three up-regulated circRNAs in HCC based on datasets GSE78520\&GSE94508\&GSE97332 and GSE135806, respectively. $\mathbf{f}$ Expression of the three identified circRNAs in the respective datasets. CHB, chronic hepatitis B patients. Data were shown as mean \pm SEM. $\mathbf{g}$ Agarose gel electrophoresis showed that divergent primers amplified hsa_circ_0009910 (left) and hsa_circ_0089172 (right) in cDNA but not genomic DNA (gDNA) from HepG2 cells. $\mathbf{h}$ Real-time PCR (top) and agarose gel electrophoresis (bottom) showed that hsa_circ_0009910 and hsa_circ_0089172 but not $\beta$-actin from HepG2 cells were insensitive to RNase R treatment. i Detection of hsa_circ_0009910 (left) and hsa_circ_0089172 (right) excretion in the indicated hepatoma cells' culture medium

\section{Statistical analysis}

Statistical analysis was performed using GraphPad Prism (version: 8.0.2) and $\mathrm{R}$ software. The survival curves were calculated using the Kaplan-Meier method, and a logrank test assessed the differences. Statistical significance was indicated by $P$ values less than 0.05 . ${ }^{*} P<0.05$, ** $P<0.01$, *** $P<0.001$, **** $P<0.0001$.

\section{Results}

\section{Three circRNAs were significantly up-regulated}

\section{both in HCC tissues and plasma samples}

To identify differentially expressed circRNAs in HCC tissues and plasma samples, four publicly available microarray datasets providing circRNA expression profile (GSE78520, GSE94508, GSE97332, and GSE135806) were collected in this study. GSE78520, GSE94508, and GSE97332 were HCC tissues-related and were all from platform GPL19978 Agilent-069978 Arraystar Human CircRNA microarray V1, whereas GSE135806 was HCC plasma samples-related and was from the platform of GPL26925 Agilent-084217 CapitalBio Technology Human CircRNA Array v2. A summary of the four datasets was presented in Table 3. First, we performed a quality check, cohort-specific normalization, and combined the three HCC tissues-related datasets by Limma, resulting in a meta-cohort of 15 pairs of HCC and matched non-tumor tissues (GSE78520\&GSE94508\&GSE97332). The principal component analysis plot indicated that the batch effect due to cohort and processing centers was effectively minimized while retaining the disease state's differences in the meta-cohort (Fig. 2a, b). A total of 687 differentially expressed circRNAs (421 up-regulated and 266 down-regulated) were identified in the pooled 15 pairs of samples (Fig. 2c, d). Previously reported differentially expressed circRNAs, including hsa_circ_0004913, hsa_circRNA_0008514, hsa_ circ_0067934, hsa_circRNA_0006461, hsa_circ_0017639, and hsa_circ_0074854 [26, 27] were also identified in our analysis (Fig. 2c), proving the robustness of the above HCC meta-cohort compilation. On the other hand, a total of 371 circRNAs were differentially expressed (326 up-regulated and 45 down-regulated) in HCC plasma samples (GSE135806 [28]). Venn diagrams and volcano plots showed three circRNAs (hsa_circ_0009910, hsa circ_0049783, and hsa_circ_0089172) were consistently up-regulated, and none were down-regulated in the integrated datasets (Fig. 2d, e). Scatter plots confirmed the increased expression of these three circRNAs in HCC tissues and plasma samples compared with their respective controls (Fig. 2f). The essential characteristics of the three identified circRNAs are displayed in Table 4. Intriguingly, regulation directions of their parent genes were different from the significantly up-regulated circRNAs, indicating that the three increased circRNAs in HCC were not by-products of splicing but were suggestive of functionality [29].

We used divergent primers specifically amplifying circRNA in cDNA but not genomic DNA, and convergent primers amplifying both circRNA and linear RNA and in cDNA and parental gene in genomic DNA to confirm that hsa_circ_0009910 and hsa_circ_0089172 were indeed circular (Fig. 2g). Following RNase R treatment, expression levels of hsa_circ_0009910 and hsa_circ_0089172 were almost unaffected. In contrast, linear $\beta$-actin was substantially digested, demonstrating that hsa_circ_0009910 and hsa_circ_0089172 were resistant to RNase R treatment and were stable transcripts (Fig. 2h). Agarose gel electrophoresis following circRNAs amplification showed that these two circRNAs existed in the culture medium of tumor cells but not in the control group, indicating hsa_circ_0009910 and hsa_circ_0089172 excretion from hepatoma cells (Fig. 2i).

\section{Identification of four circRNA-miRNA interactions}

To depict whether the three up-regulated circRNAs could regulate gene expression by functioning as miRNA sponges in HCC, we collected their basic structural patterns from the CSCD database, exhibiting numerous miRNA response elements (MREs; Fig. 3a). We further collected their potential miRNA bindings by intersecting the MREs predicted by two web tools, CSCD and circbank (Fig. 3b). A total of five miRNAs (hsa-miR455-5p, hsa-miR-615-3p, hsa-miR-3926, hsa-miR5197-3p, and hsa-miR-6836-3p) were identified for 


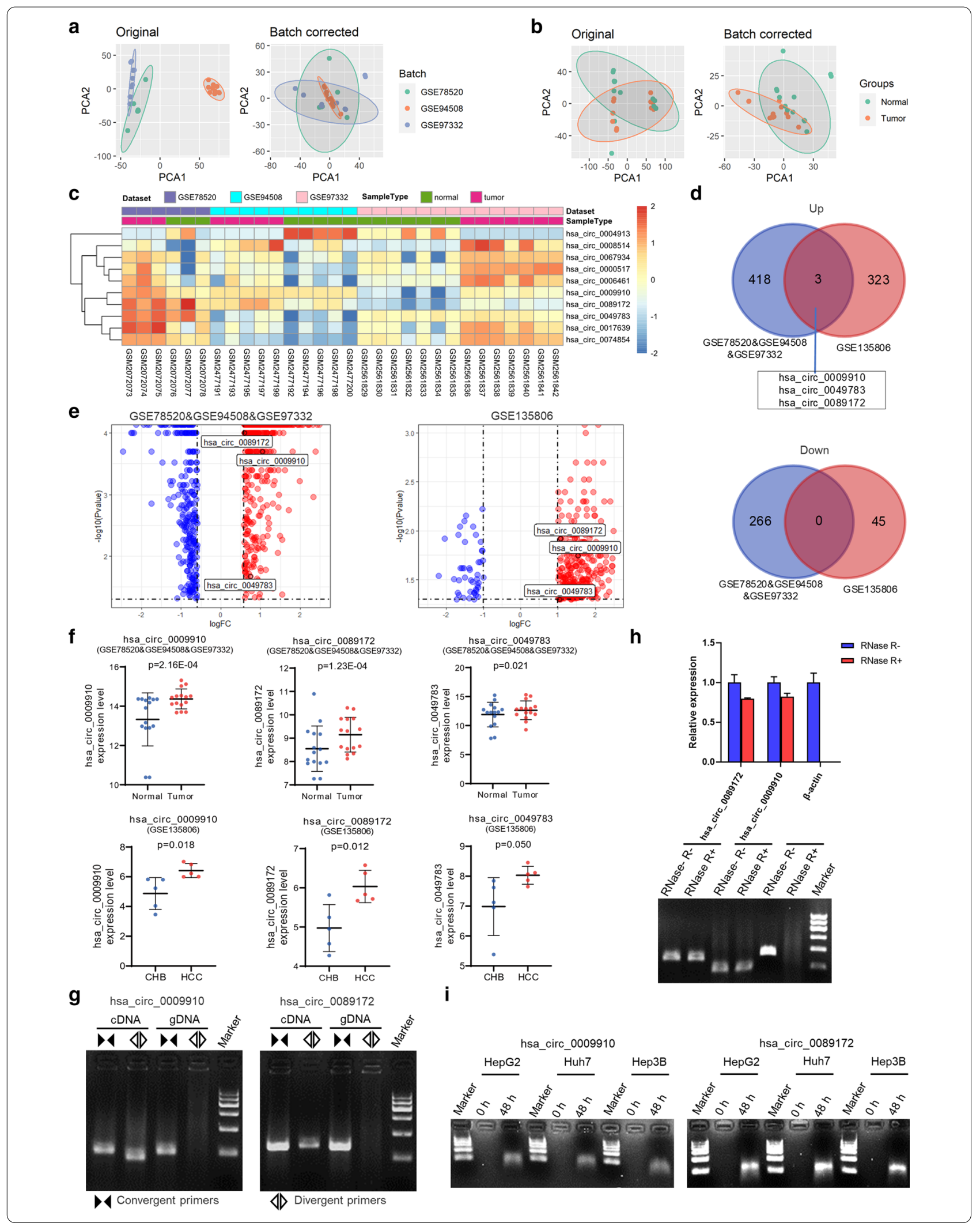


Table 3 Basic information of datasets used in this study

\begin{tabular}{|c|c|c|c|c|c|}
\hline Dataset & Platform & $\begin{array}{l}\text { Sample size } \\
\text { (tumor/non-tumor) }\end{array}$ & Race & Data type & Cut-off \\
\hline GSE78520 & GPL19978 & $3 / 3$ & Chinese & \multirow{3}{*}{$\begin{array}{l}\text { CircRNA expression profile in HCC and matched } \\
\text { non-tumor tissues }\end{array}$} & \multirow{3}{*}{$\begin{array}{l}\mid \log 2(\text { foldchange }) \mid \geq 0.585 \\
P<0.05\end{array}$} \\
\hline GSE94508 & GPL19978 & $5 / 5$ & Chinese & & \\
\hline GSE97332 & GPL19978 & $7 / 7$ & Chinese & & \\
\hline GSE135806 & GPL26925 & $5 / 5$ & Chinese & $\begin{array}{l}\text { CircRNA expression in the plasma from HBV- } \\
\text { related HCC and chronic hepatitis B patients }\end{array}$ & $\begin{array}{l}\mid \log 2(\text { foldchange }) \mid \geq 1 \\
P<0.05\end{array}$ \\
\hline GSE14520 & GPL3921 & $225 / 220$ & Chinese & $\begin{array}{l}\text { Gene expression data of HBV-related HCC and } \\
\text { paired non-tumor tissues }\end{array}$ & $\begin{array}{l}\mid \log 2(\text { foldchange }) \mid \geq 1 \\
P<0.01\end{array}$ \\
\hline TCGA-LIHC & Illumina HiSeq & $374 / 50$ & $\begin{array}{l}\text { mixed Asian/ } \\
\text { European } \\
\text { origin }\end{array}$ & $\begin{array}{l}\text { Gene expression RNAseq of tumor and normal } \\
\text { tissues }\end{array}$ & $\begin{array}{l}\mid \log 2(\text { foldchange }) \mid \geq 1 \\
P<0.01\end{array}$ \\
\hline GSE76903 & Illumina HiSeq & $20 / 20$ & Chinese & $\begin{array}{c}\text { miRNA-seq of matched adjacent normal and } \\
\text { primary tumor samples from HCC patients }\end{array}$ & average normalized count $\geq 1$ \\
\hline
\end{tabular}

TCGA-LIHC The Cancer Genome Atlas Liver Hepatocellular Carcinoma

Table 4 The three up-regulated exonic circRNAs and the expression of their parent genes in TCGA-LIHC and GSE14520GPL3921

\begin{tabular}{|c|c|c|c|c|c|c|c|c|c|}
\hline ID in circBase & Position & Strand & $\begin{array}{l}\text { Genomic } \\
\text { length }\end{array}$ & $\begin{array}{l}\text { Spliced } \\
\text { length }\end{array}$ & $\begin{array}{l}\text { CircRNA } \\
\text { regulation }\end{array}$ & $\begin{array}{l}\text { Parent gene } \\
\text { symbol }\end{array}$ & $\begin{array}{l}\text { Parent } \\
\text { gene } \\
\text { regulation } \\
\text { in TCGA- } \\
\text { LIHC }\end{array}$ & $\begin{array}{l}\text { Parent gene } \\
\text { regulation } \\
\text { in GSE14520 }\end{array}$ & $\begin{array}{l}\text { CircRNA vs. } \\
\text { parent gene } \\
\text { regulation } \\
\text { direction }\end{array}$ \\
\hline $\begin{array}{l}\text { hsa_- } \\
\text { circ_0009910 }\end{array}$ & $\begin{array}{c}\text { chr1:12,049,221- } \\
12,052,747\end{array}$ & + & 3526 & 315 & Up & MFN2 & Up & No significant & Different \\
\hline $\begin{array}{l}\text { hsa_- } \\
\text { circ_0049783 }\end{array}$ & $\begin{array}{c}\text { chr19:14,705,328- } \\
14,705,612\end{array}$ & + & 284 & 126 & Up & CLEC17A & $\begin{array}{l}\text { No signifi- } \\
\text { cant }\end{array}$ & Not available & Different \\
\hline $\begin{array}{l}\text { hsa_- } \\
\text { circ_0089172 }\end{array}$ & $\begin{array}{c}\text { chr9: } 134,049,441- \\
134,053,797\end{array}$ & + & 4356 & 526 & Up & NUP214 & Up & No significant & Different \\
\hline
\end{tabular}

hsa_circ_0009910, two miRNAs (hsa-miR-18a-3p and hsa-miR-8071) for hsa_circ_0049783, and three miRNAs (hsa-miR-4524a-3p, hsa-miR-3154, hsa-miR-3190-5p) for hsa_circ_0089172. Among these miRNAs, 4 (hsamiR-455-5p, hsa-miR-615-3p, hsa-miR-18a-3p, hsa-miR$4524 a-3 p)$ are expressed in primary HCC or matched adjacent normal tissues (average normalized count $\geq 1$ ) according to a recent study providing genome-wide miRNA expression profile (Fig. 3c; Table 5). Thus, a total of four circRNA-miRNA interactions, including three circRNAs and four miRNAs were identified.

\section{Construction of circRNA-miRNA-mRNA network}

A total of 12,908 target genes of the four miRNAs mentioned above were obtained from miRWalk, a web tool for predicting miRNA binding sites. Additionally, 6648 genes were significantly up-regulated in tumors compared with normal tissues from The Cancer Genome Atlas Liver Hepatocellular Carcinoma (TCGA-LIHC) with mixed Asian/European origin, while 337 increased genes from GSE14520 dataset from a Chinese cohort
(Fig. 4a). To further narrow the scope, we intersected the miRNA targets predicted by miRWalk with the significantly up-regulated genes determined from TCGA-LIHC and GSE14520, resulting in a total of 95 candidate genes for further analysis (Fig. 4b). By integrating the circRNAmiRNA and miRNA-mRNA interactions, we established and visualized a circRNA-miRNA-mRNA regulatory network in HCC (Fig. 4c).

\section{Identification of 19 hub genes}

Figuring out the biological function of potential circRNA-related genes could predict the corresponding function of circRNAs. Interactions among the 95 candidate genes were predicted with the STRING tool, leading to a network containing 67 nodes and 358 edges after removing unconnected nodes (Fig. 5a). Subsequently, we employed the MCODE clustering algorithm to find hub genes from the interaction network. One subnetwork with 19 significantly up-regulated nodes and 166 edges was identified with the $\mathrm{k}$-core $=2$ (Fig. 5b, c, and Table 2), suggesting the 19 hub genes' critical roles in HCC. 


\section{a}

MRE (microRNA response element)

RBP (RNA binding protein)

ORF (open reading frame)

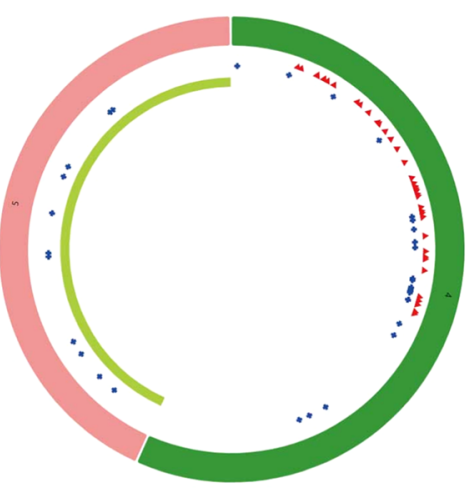

hsa_circ_0009910

b

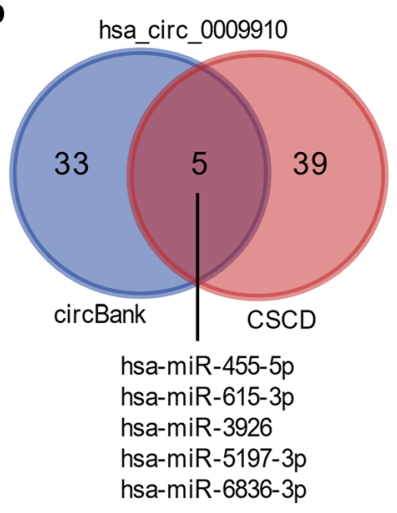

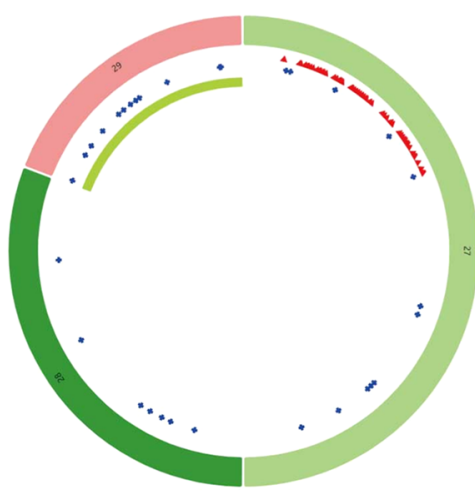

hsa_circ_0089172

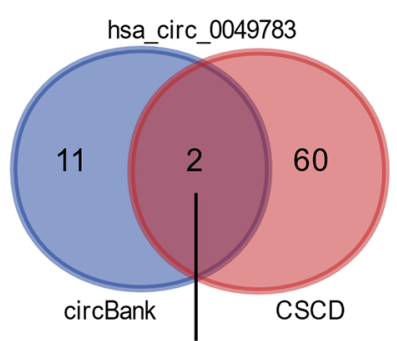

hsa-miR-18a-3p hsa-miR-8071

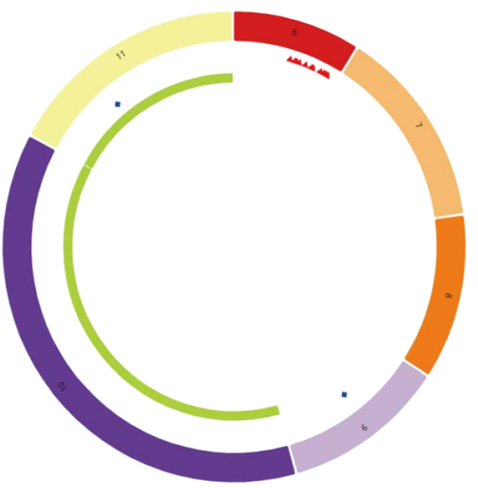

hsa_circ_0049783

C
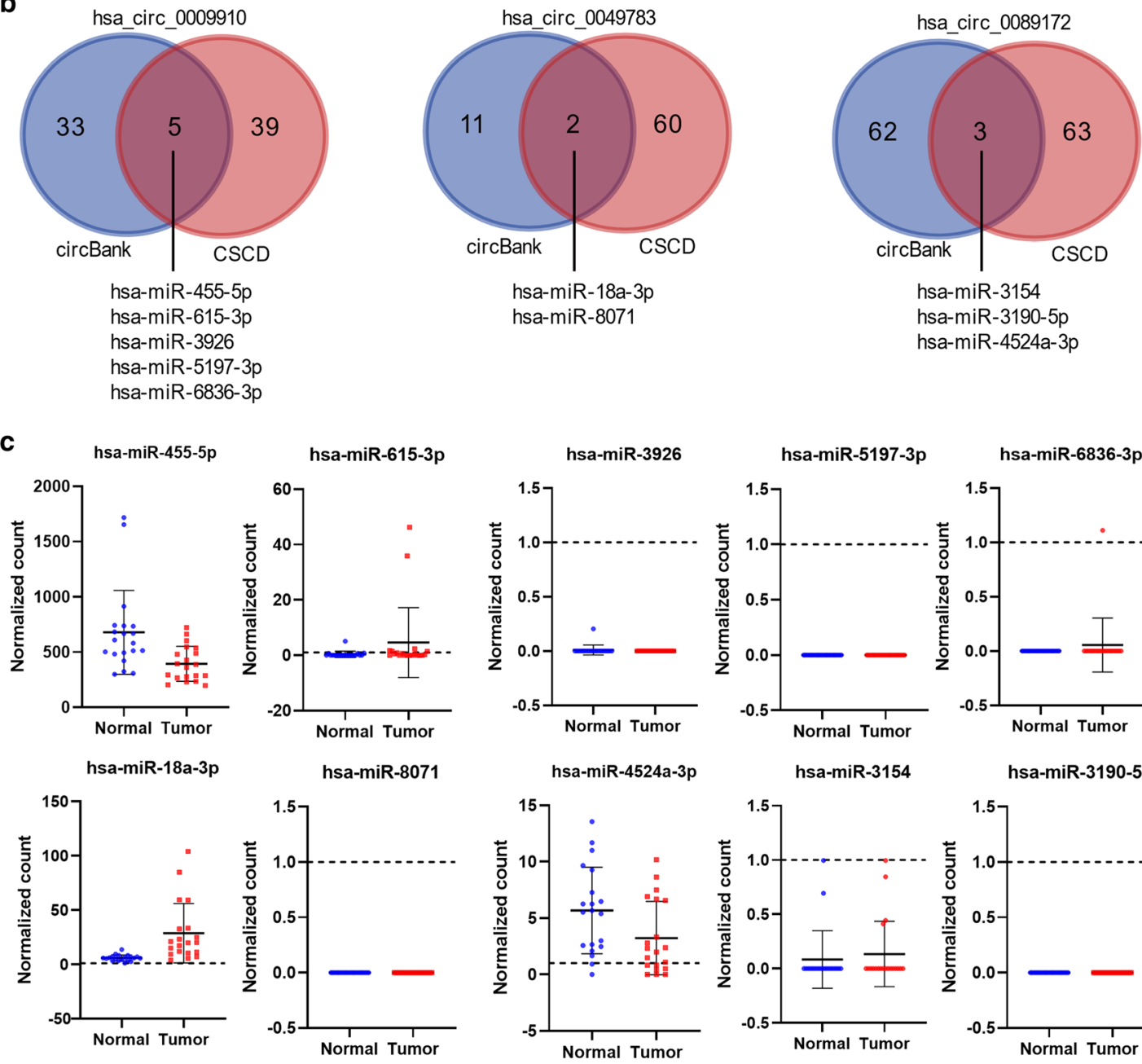

Fig. 3 Identification of circRNA-miRNA interactions. a Structural patterns of the three circRNAs by the Cancer-specific circRNAs database (CSCD). $\mathbf{b}$ Prediction of miRNA binding by circBank and CSCD. c Expression of the ten candidate miRNAs in the miRNA-seq dataset GSE76903 
Table 5 The target miRNAs of three circRNAs predicted by circBank and CSCD

\begin{tabular}{lllllll}
\hline circRNA & miRNA & $\begin{array}{l}\text { miRanda } \\
\text { binding } \\
\text { position }\end{array}$ & MSA Start & MSA End & Site Type & $\begin{array}{l}\text { Expressed in primary HCC or matched } \\
\text { adjacent normal tissues according } \\
\text { to GSE76903* }\end{array}$ \\
\hline hsa_circ_0009910 & hsa-miR-455-5p & 273 & 23 & 29 & 7 mer-m8 & Yes \\
& hsa-miR-615-3p & 266 & 15 & 22 & 8 mer-1a & Yes \\
& hsa-miR-3926 & 296 & 43 & 49 & 7 mer-m8 & No \\
& hsa-miR-5197-3p & 1 & 65 & 71 & 7 mer-m8 & No \\
hsa_circ_0049783 & hsa-miR-6836-3p & 270 & 20 & 26 & 7 mer-m8 & No \\
& hsa-miR-18a-3p & 12 & 78 & 84 & 7 mer-m8 & Yes \\
hsa_circ_0089172 & hsa-miR-8071 & 97 & 62 & 68 & 7 mer-1a & No \\
& hsa-miR-4524a-3p & 160 & 57 & 63 & $7 m e r-m 8$ & Yes \\
& hsa-miR-3154 & 494 & 33 & 40 & 8 mer-1a & No \\
& hsa-miR-3190-5p & 397 & 50 & 55 & 6 mer & No \\
\hline
\end{tabular}

* average normalized count $\geq 1$

\section{Twelve hub genes with prognostic values}

To investigate the prognostic values of the hub genes, survival analysis was performed on patients from TCGALIHC and GSE14520. Kaplan-Meier's survival curves showed that among the 19 hub genes, high expression of 12 genes, including MCM6, CCNB1, CDC20, NDC80, ZWINT, ASPM, CENPU, MCM3, MCM5, ECT2, CDC7, and DLGAP5 was significantly associated with poorer overall survival (Log-rank $P<0.05$ ) in patients from TCGA-LIHC and GSE14520 (Fig. 6; Table 2). Correlations between expression levels of these 12 hub genes and reduced disease-free interval, disease-specific survival, and progression-free interval were also observed in patients from TCGA-LIHC (hazard ratio $>1$; Table 6). A circRNA-miRNA-hub gene network consisting of four regulatory modules (hsa_circ_0009910-hsa-miR455-5p-DLGAP5/MCM5 axis, hsa_circ_0009910-hsamiR-615-3p-MCM5/MCM6/MCM3/CDC20/CCNB1/ CDC7 axis, hsa_circ_0049783-hsa-miR-18a-3p-ZWINT axis, and hsa_circ_0089172-hsa-miR-4524a-3p-CDC7/ CCNB1/CENPU/ASPM/ECT2/NDC80 axis) was then built to delineate the links among the identified circRNAs, miRNAs and hub genes (Fig. 7a).

\section{Functional enrichment analysis of hub genes}

Enrichment analysis was performed to illustrate the functional annotations of the 12 survival-related hub genes. KEGG pathway enrichment analysis indicated that hub genes were mainly enriched in DNA replication and cell cycle. For the Reactome pathways, the hub genes were enriched in activation of the pre-replicative complex, G1/S transition, resolution of sister chromatid cohesion, and DNA replication. For the Wikipathway, enrichment of the hub genes in regulation of sister chromatid separation at the metaphase-anaphase transition, DNA replication, and retinoblastoma gene in cancer was identified (Fig. 7b-d).

\section{Discussion}

In recent years, the application of large-scale gene expression profiling and the development of bioinformatics has allowed us to systematically uncover the molecular regulation mechanisms associated with tumorigenesis and development. However, large sample sizes are required to identify circRNA expression differences with greater statistical power [30]. In this study, we obtained three up-regulated circRNAs, namely hsa_circ_0009910, hsa circ_0049783, and hsa_circ_0089172, through jointly analyzing of three tissue microarray datasets and a blood microarray dataset, suggesting these deregulated circRNAs in HCC tissues could be secreted into plasma [28]. Recent studies found that hsa_circ_0009910 was overexpressed in osteosarcoma and ovarian cancer cells, acting as a sponge of miR-449a and promoting the expression of miR-449a target IL6R in osteosarcoma while suppressing miR-145 in ovarian cancer cells [31, 32]. The expression of hsa_circ_0089172 was up-regulated in Hashimoto's thyroiditis patients and might function via sponging miR125a-3p [33]. However, the role of hsa_circ_0049783 has not been reported.

To explore the interaction of the candidate circRNAs with miRNA and mRNA, we constructed a circRNA-miRNA-mRNA regulatory network based on the mechanism that circRNAs harboring miRNA 


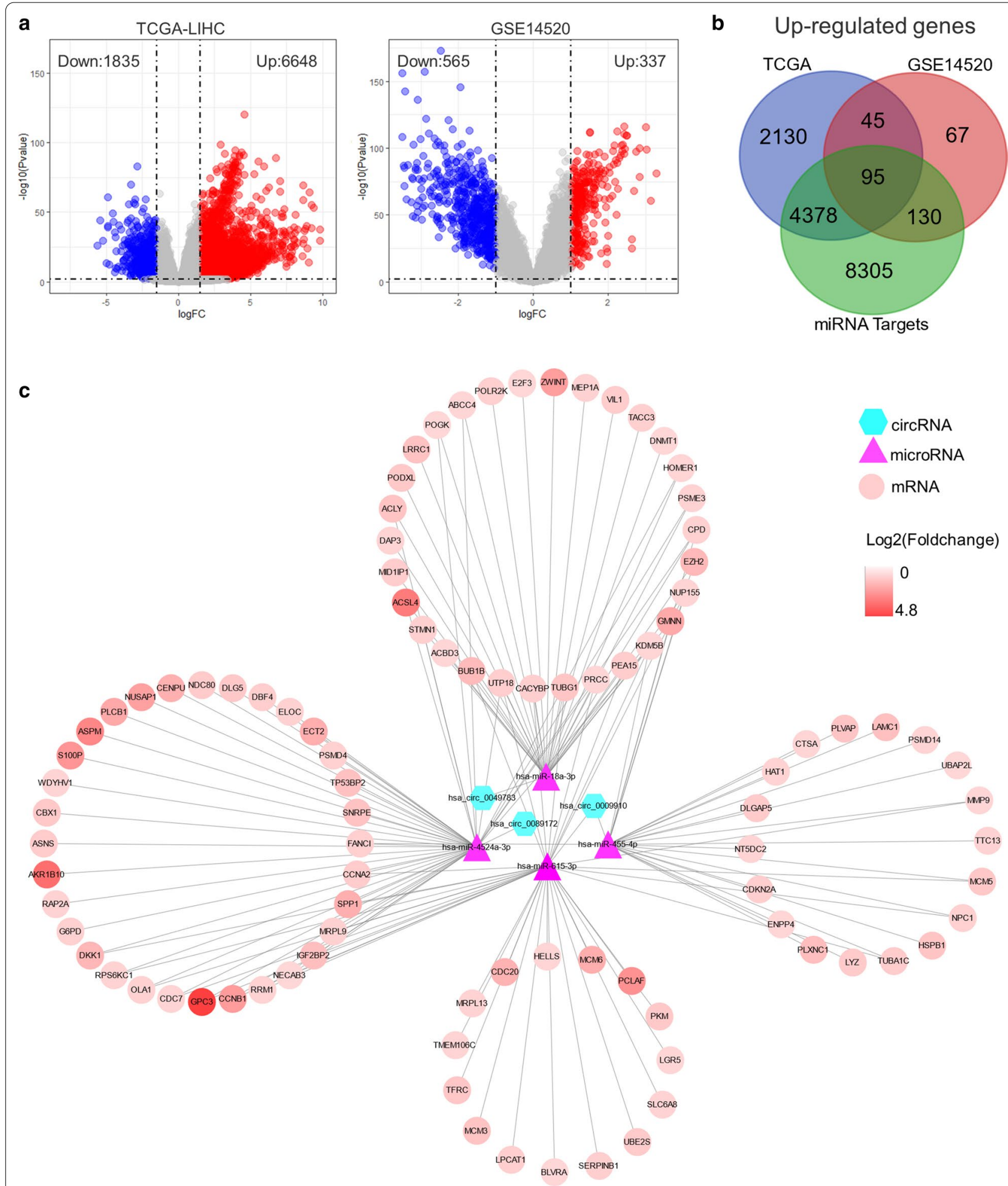

Fig. 4 Construction of circRNA-miRNA-mRNA regulatory network. a Volcano plot of significantly differentially expressed genes in TCGA-LIHC (left) and GSE14520 (right). b Venn diagram shows the intersections between miRNA targets predicted by miRWalk, significantly up-regulated genes from TCGA-LIHC and GSE14520. c A circRNA-miRNA-mRNA network consisting of three cricRNAs, four miRNAs, and 95 genes 


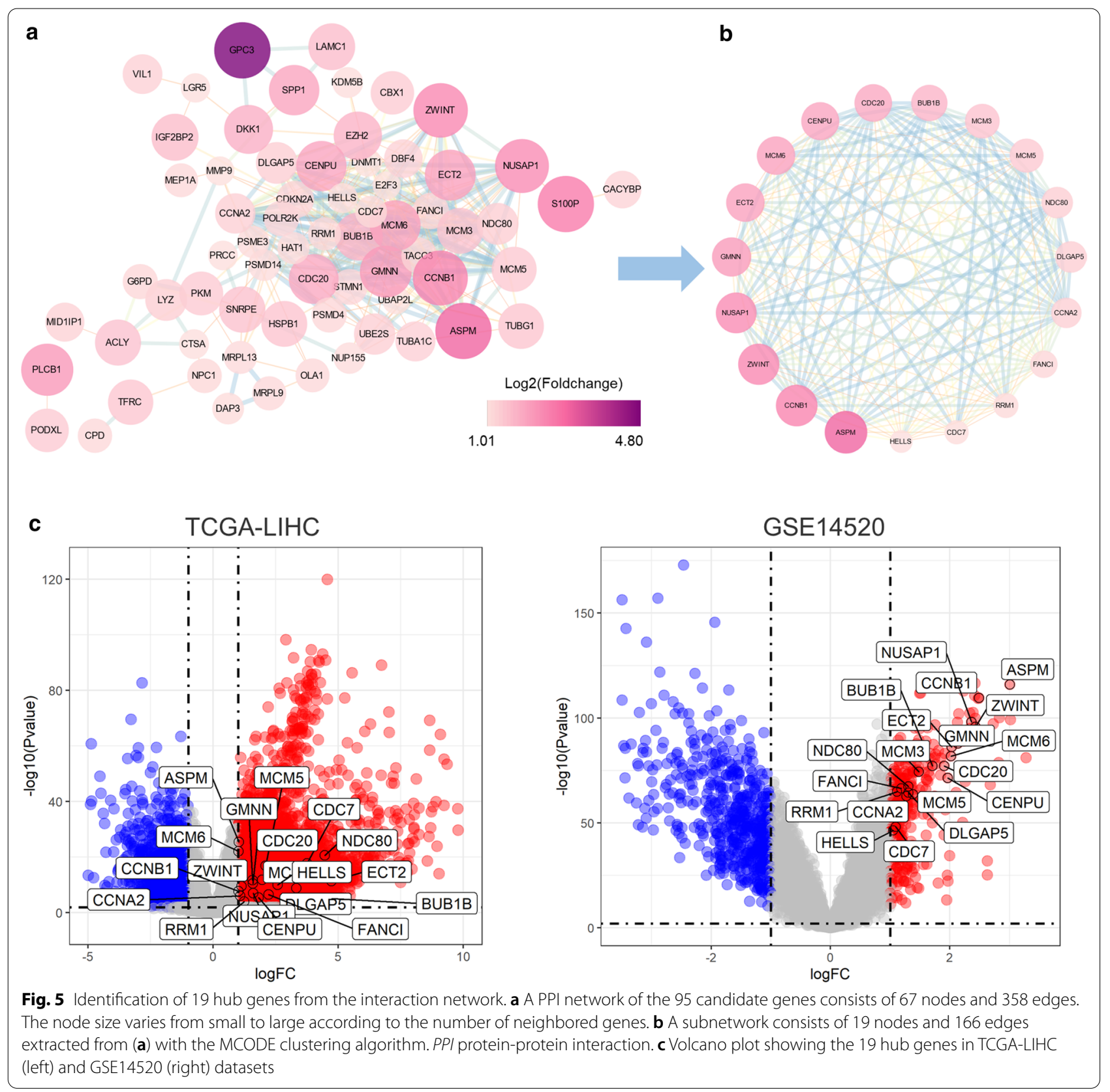

binding sites might act as miRNA sponges to regulate downstream gene expression [34]. A total of four miRNAs, namely hsa-miR-455-5p, hsa-miR-615-3p, hsamiR-18a-3p, and hsa-miR-4524a-3p, were screened out to interact with the candidate circRNAs. Cumulative evidence indicates that hsa-miR-455-5p functions as a tumor suppressor in cancer progression of stomach and prostate [35, 36]. Hsa-miR-615-3p has also been reported as a tumor suppressor in cancers of lung and esophagus [37]. Downstream hub genes, including MCM6, CCNB1, CDC20, NDC80, ZWINT, ASPM,
CENPU, MCM3, MCM5, ECT2, CDC7, and DLGAP5, were up-regulated and associated with reduced survival in two HCC cohorts. Our enrichment analysis showed that these hub genes were mainly enriched in DNA replication and cell cycle, indicating their critical roles in the pathogenesis of HCC. Consistently, Jia et al. suggested that MCM6 could be an optimal diagnostic biomarker and a potential therapeutic target for HCC in a Southern Chinese Zhuang population [38]. Ju et al. proved that the expression level of NDC80 was significantly elevated in HCC tissues and contributed 

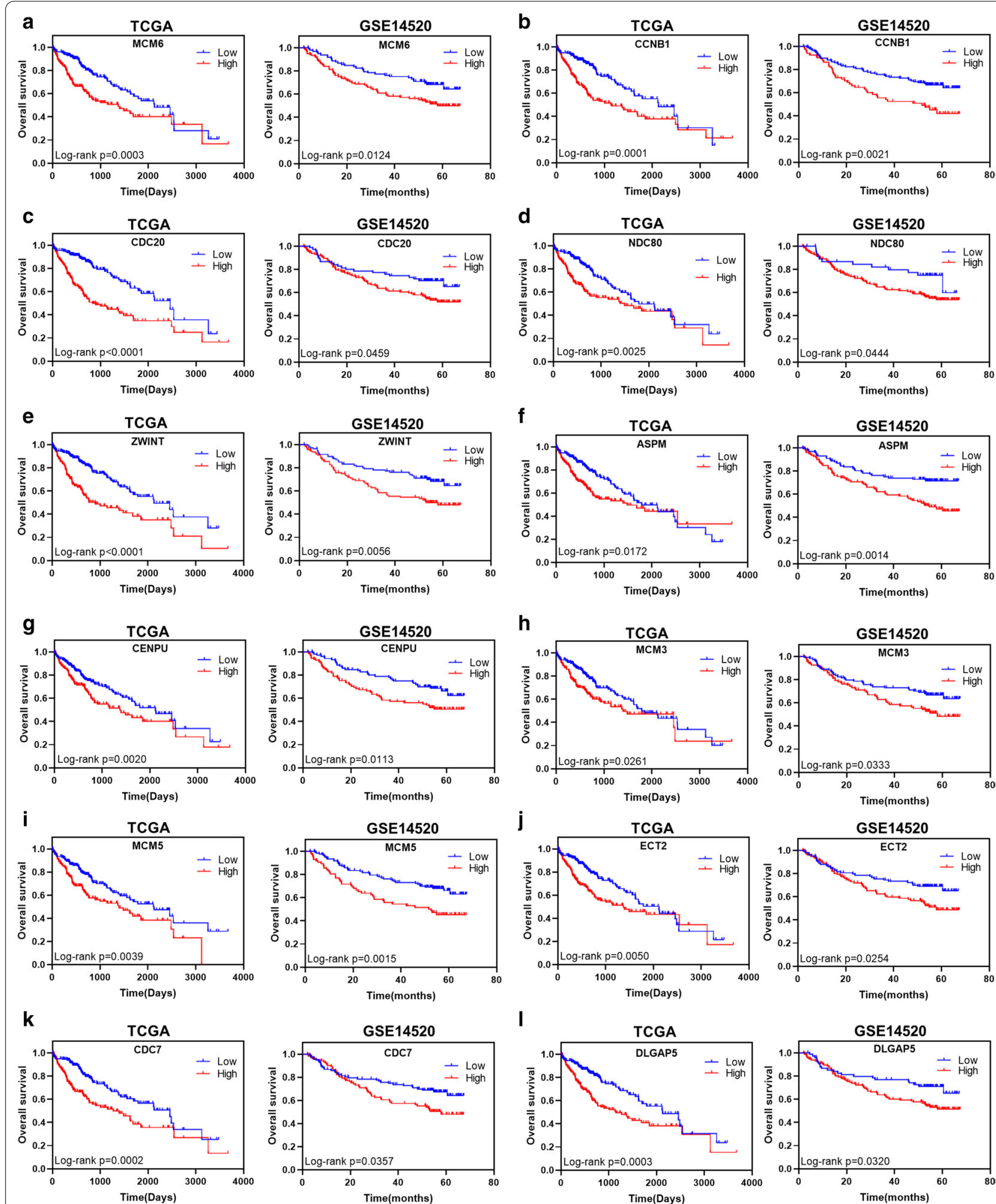

I
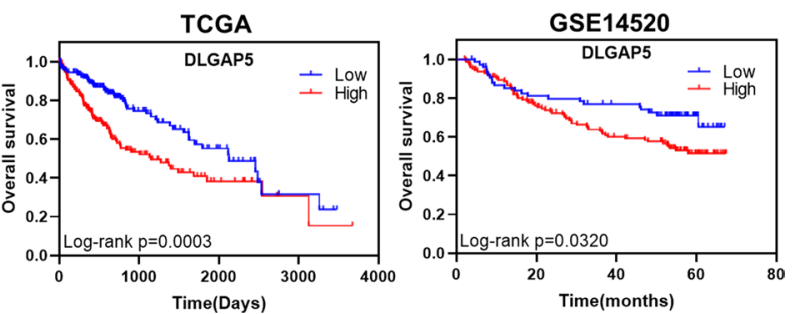

Fig. 6 Kaplan-Meier's survival curves showed the correlations between expression levels of 12 hub genes and reduced overall survival. A log-rank test was used 
Table 6 Survival analysis for 12 significantly up-regulated hub genes in TCGA-LIHC

\begin{tabular}{|c|c|c|c|c|c|c|}
\hline \multirow[t]{2}{*}{ Hubgenes } & \multicolumn{2}{|l|}{ DFI } & \multicolumn{2}{|l|}{ DSS } & \multicolumn{2}{|l|}{ PFI } \\
\hline & $\mathrm{HR}(95 \% \mathrm{Cl})$ & Log-rank $P$ value & $\mathrm{HR}(95 \% \mathrm{Cl})$ & Log-rank $P$ value & $\mathrm{HR}(95 \% \mathrm{Cl})$ & Log-rank $P$ value \\
\hline MCM6 & $1.923(1.358-2.724)$ & $<0.0001^{* * * *}$ & $1.901(1.217-2.971)$ & $0.0040^{* *}$ & $1.865(1.386-2.510)$ & $<0.0001^{* * * *}$ \\
\hline CCNB1 & $1.847(1.323-2.578)$ & $0.0002^{* * *}$ & $2.189(1.404-3.412)$ & $0.0005^{* * *}$ & $1.947(1.447-2.619)$ & $<0.0001^{* * * *}$ \\
\hline CDC20 & $1.614(1.144-2.278)$ & $0.0038^{* *}$ & $3.028(1.936-4.736)$ & $<0.0001^{* * * *}$ & $1.809(1.345-2.434)$ & $<0.0001^{* * * *}$ \\
\hline NDC80 & $1.497(1.077-2.081)$ & $0.0155^{*}$ & $1.786(1.145-2.786)$ & $0.0098^{* *}$ & $1.501(1.118-2.015)$ & $0.0061^{* *}$ \\
\hline ZWINT & $2.076(1.466-2.938)$ & $<0.0001^{* * * *}$ & $2.170(1.390-3.389)$ & $0.0006^{* * *}$ & $1.899(1.377-2.499)$ & $<0.0001^{* * * *}$ \\
\hline ASPM & $1.419(1.022-1.972)$ & $0.0360^{*}$ & $1.794(1.135-2.767)$ & $0.0104^{*}$ & $1.432(1.068-1.920)$ & $0.0158^{*}$ \\
\hline CENPU & $1.497(1.077-2.081)$ & $0.0155^{*}$ & $1.786(1.145-2.786)$ & $0.0098^{* *}$ & $1.501(1.118-2.015)$ & $0.0061^{* *}$ \\
\hline MCM3 & $1.615(1.160-2.248)$ & $0.0039^{* *}$ & $1.734(1.109-2.711)$ & $0.0131^{*}$ & $1.627(1.210-2.186)$ & $0.0010^{* *}$ \\
\hline MCM5 & $1.372(0.986-1.908)$ & 0.0576 & $1.623(1.040-2.532)$ & $0.0305^{*}$ & $1.446(1.076-1.942)$ & $0.0128^{*}$ \\
\hline ECT2 & $1.488(1.070-2.070)$ & $0.0168^{*}$ & $2.084(1.338-3.245)$ & $0.0013^{* *}$ & $1.564(1.166-2.098)$ & $0.0026^{* *}$ \\
\hline CDC7 & $1.255(0.902-1.745)$ & 0.1726 & $2.151(1.376-3.364)$ & $0.0006^{* * *}$ & $1.453(1.073-1.967)$ & $0.0128^{*}$ \\
\hline DLGAP5 & $1.484(1.067-2.064)$ & $0.0177^{*}$ & $2.262(1.452-3.525)$ & $0.0004^{* * *}$ & $1.671(1.245-2.243)$ & $0.0005^{* * *}$ \\
\hline
\end{tabular}

$H R$ hazard ratio, DFI disease-free interval, DSS disease specific survival, $P F I$ progression free interval

to tumor progression [39]. Ying et al. reported that ZWINT was overexpressed in HCC samples and associated with poor overall survival and tumor recurrence [40]. Lin et al. suggested that ASPM overexpression was a marker for enhanced vascular invasive, metastatic potential, and poor prognosis of HCC [41]. Chen et al. identified that the ECT2 upregulation was associated with early HCC recurrence and poor survival [42]. Liao et al. reported that DLGAP5 was significantly up-regulated in HCC specimens and promoted cell proliferation [43].

\section{Conclusions}

In summary, we screened out three novel circRNAs upregulated both in tissue and plasma from HCC patients and constructed a regulatory mechanism of circRNAmiRNA-mRNA interaction by integrating multiple expression profiles and bioinformatics tools. Our study provides a new perspective on the effectiveness of the candidate circRNAs as biomarkers and clinical treatment targets for HCC. 
a

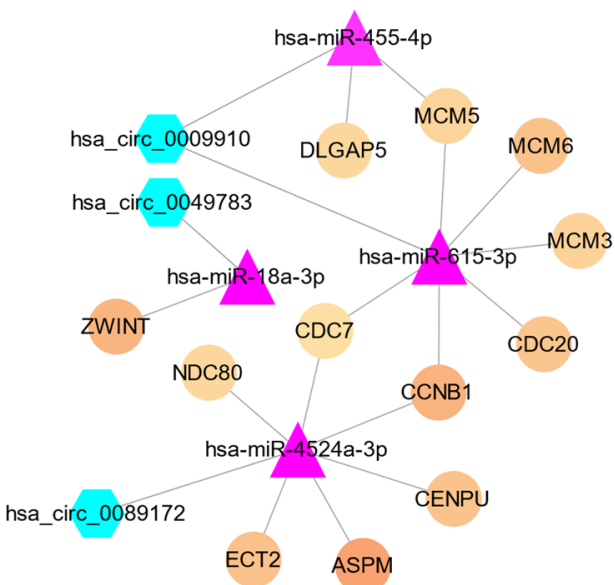

KEGG

b

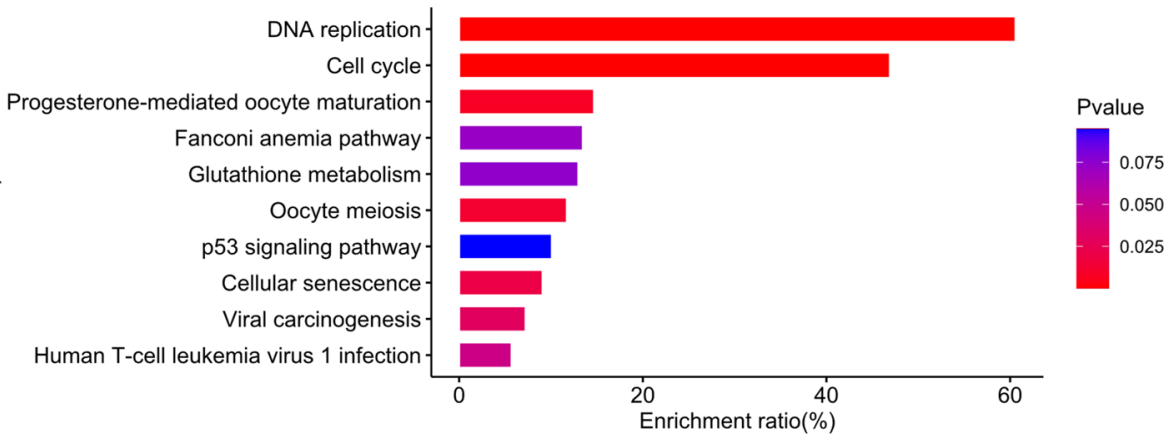

C

Reactome

Activation of the pre-replicative complex Activation of ATR in response to replication stress DNA Replication Pre-Initiation G1/S Transition Resolution of Sister Chromatid Cohesion DNA Replication Mitotic G1-G1/S phases Cell Cycle Checkpoints Cell Cycle, Mitotic Cell Cycle

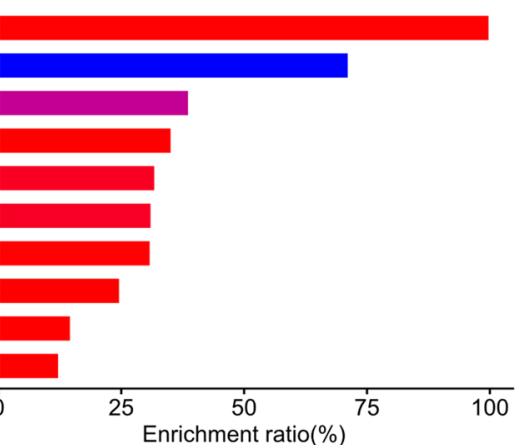

d

Wikipathway

Regulation of sister chromatid separation at the metaphase-anaphase transition DNA Replication.

Retinoblastoma Gene in Cancer Biomarkers for pyrimidine metabolism disorders $\mathrm{G} 1$ to $\mathrm{S}$ cell cycle control.

Pyrimidine metabolism and related diseasesCell Cycle. Nucleotide Metabolism AMP-activated Protein Kinase (AMPK) Signaling Ciliary landscap

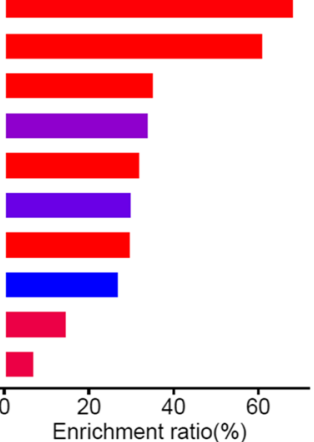

Pvalue

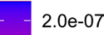
$1.5 \mathrm{e}-07$ $1.0 \mathrm{e}-07$ 5.0e-08

Fig. 7 CircRNA-miRNA-hub gene network and pathway enrichment analysis. a A CircRNA-miRNA-hub gene network consisting of three cricRNAs, four miRNAs, and 12 hub genes. b-d Enrichment analysis of the 12 survival-related hub genes. b KEGGpathway. c Reactome pathway. $\mathbf{d}$ Wikipathway 


\section{Acknowledgements \\ Not applicable.}

\section{Authors' contributions}

$L W, L Z, X W$, and XC conceived the study. LW, LZ, JH, JM, and KL searched and analyzed the data. LW and LZ wrote the draft of the paper. LW, LZ, XW, and $X C$ revised the manuscript. All authors have read and approved the final manuscript.

\section{Funding}

This work was supported by the National Natural Science Foundation of China (No. 82060513, 82060297, 82060579, and 81902850), the Youth Science and Technology Innovation Leading Talents Project of Corps (2020CB015), and the Youth Innovation Talents Project of Shihezi University (CXBJ201907).

\section{Availability of data and materials}

All data generated or analysed during this study are included in this published article.

\section{Ethics approval and consent to participate}

Not applicable.

\section{Consent for publication}

Not applicable.

\section{Competing interests}

The authors declare that they have no competing interests.

Received: 5 November 2020 Accepted: 6 January 2021

Published online: 22 January 2021

\section{References}

1. Villanueva A. Hepatocellular Carcinoma. N Engl J Med. 2019;380(15):1450-62.

2. Llovet JM, Zucman-Rossi J, Pikarsky E, Sangro B, Schwartz M, Sherman M, Gores G. Hepatocellular carcinoma. Nature Rev Dis Primers. 2016:2:16018.

3. Wang M, Yu F, Li P. Circular RNAs: Characteristics, Function and Clinical Significance in Hepatocellular Carcinoma. Cancers 2018, 10(8).

4. Llovet JM, Montal R, Sia D, Finn RS. Molecular therapies and precision medicine for hepatocellular carcinoma. Nature Rev Clin Oncol. 2018;15(10):599-616.

5. Qiu LP, Wu YH, Yu XF, Tang Q, Chen L, Chen KP. The Emerging Role of Circular RNAs in Hepatocellular Carcinoma. J Cancer. 2018;9(9):1548-59.

6. Vicens Q, Westhof E. Biogenesis of Circular RNAs. Cell. 2014;159(1):13-4

7. Chen LL. The biogenesis and emerging roles of circular RNAs. Nature Rev Molecular Cell Biol. 2016:17(4):205-11.

8. Ji P, Wu W, Chen S, Zheng Y, Zhou L, Zhang J, Cheng H, Yan J, Zhang S, Yang $\mathrm{P}$, et al. Expanded expression landscape and prioritization of circular RNAs in mammals. Cell Rep. 2019:26(12):3444-60 e3445.

9. Bahn JH, Zhang Q, Li F, Chan TM, Lin X, Kim Y, Wong DT, Xiao X. The landscape of microRNA, Piwi-interacting RNA, and circular RNA in human saliva. Clinical Chem. 2015;61(1):221-30.

10. Li Z, Huang C, Bao C, Chen L, Lin M, Wang X, Zhong G, Yu B, Hu W, Dai L, et al. Exon-intron circular RNAs regulate transcription in the nucleus. Nat Struct Mol Biol. 2015;22(3):256-64.

11. Quan G, Li J. Circular RNAs: biogenesis, expression and their potential roles in reproduction. Journal\&nbsp; Ovarian Res. 2018;11(1):9.

12. Zhong Z, Huang M, Lv M, He Y, Duan C, Zhang L, Chen J. Circular RNA MYLK as a competing endogenous RNA promotes bladder cancer progression through modulating VEGFANEGFR2 signaling pathway. Cancer Lett. 2017:403:305-17

13. Chen I, Chen CY, Chuang TJ. Biogenesis, identification, and function of exonic circular RNAs. Wiley Interdis Rev RNA. 2015;6(5):563-79.

14. Zheng Q, Bao C, Guo W, Li S, Chen J, Chen B, Luo Y, Lyu D, Li Y, Shi G, et al. Circular RNA profiling reveals an abundant circHIPK3 that regulates cell growth by sponging multiple miRNAs. Nature Commun. 2016;7:11215.

15. Li X, Yang L, Chen LL. The Biogenesis, Functions, and Challenges of Circular RNAs. Molecular cell . 2018:71(3):428-442.
16. Zhang Z, Yang T, Xiao J. Circular RNAs: Promising Biomarkers for Human Diseases. EBioMedicine. 2018:34:267-74.

17. Shang $Q$, Yang $Z$, Jia R, Ge S. The novel roles of circRNAs in human cancer. Mol Cancer. 2019;18(1):6.

18. Bai N, Peng E, Qiu X, Lyu N, Zhang Z, Tao Y, Li X, Wang Z. circFBLIM1 act as a ceRNA to promote hepatocellular cancer progression by sponging miR-346. J Exp Clin Cancer Res. 2018:37(1):172.

19. Yao Z, Luo J, Hu K, Lin J, Huang H, Wang Q, Zhang P, Xiong Z, He C, Huang Z, et al. ZKSCAN1 gene and its related circular RNA (circZKSCAN1) both inhibit hepatocellular carcinoma cell growth, migration, and invasion but through different signaling pathways. Molecular oncol. 2017:11(4):422-37.

20. Wan C, Sun Y, Tian Y, Lu L, Dai X, Meng J, Huang J, He Q, Wu B, Zhang $Z$, et al. Irradiated tumor cell-derived microparticles mediate tumor eradication via cell killing and immune reprogramming. Sci Adv. 2020;6(13):eaay9789.

21. Xia S, Feng J, Chen K, Ma Y, Gong J, Cai F, Jin Y, Gao Y, Xia L, Chang H, et al. CSCD: a database for cancer-specific circular RNAs. Nucleic Acids Res. 2018;46(D1):D925-9.

22. Yang Y, Chen L, Gu J, Zhang H, Yuan J, Lian Q, Lv G, Wang S, Wu Y, Yang YT, et al. Recurrently deregulated IncRNAs in hepatocellular carcinoma. Nature Commun. 2017:8:14421.

23. Sticht C, De La Torre C, Parveen A, Gretz N. miRWalk: An online resource for prediction of microRNA binding sites. PloS ONE. 2018:13(10):e0206239.

24. Su G, Morris JH, Demchak B, Bader GD. Biological network exploration with Cytoscape 3. Current Protocols Bioinform. 2014:47:8.13.11-24.

25. Bader GD, Hogue CW. An automated method for finding molecular complexes in large protein interaction networks. BMC Bioinform. 2003:4:2.

26. Li Q, Pan X, Zhu D, Deng Z, Jiang R, Wang X. Circular RNA MAT2B promotes glycolysis and malignancy of hepatocellular carcinoma through the miR-338-3p/PKM2 Axis under hypoxic stress. Hepatology. 2019;70(4):1298-316.

27. Xiong DD, Dang YW, Lin P, Wen DY, He RQ, Luo DZ, Feng ZB, Chen G. A circRNA-miRNA-mRNA network identification for exploring underlying pathogenesis and therapy strategy of hepatocellular carcinoma. J Translational Med. 2018;16(1):220.

28. Yu J, Ding WB, Wang MC, Guo XG, Xu J, Xu OG, Yang Y, Sun SH, Liu JF, Oin $\mathrm{LX}$, et al. Plasma circular RNA panel to diagnose hepatitis B virus-related hepatocellular carcinoma: A large-scale, multicenter study. Int J Cancer. 2020;146(6):1754-63.

29. Yu J, Xu OG, Wang ZG, Yang Y, Zhang L, Ma JZ, Sun SH, Yang F, Zhou WP. Circular RNA cSMARCA5 inhibits growth and metastasis in hepatocellular carcinoma. J Hepatol. 2018;68(6):1214-27.

30. Tan TZ, Rouanne M, Tan KT, Huang RY, Thiery JP. Molecular Subtypes of Urothelial Bladder Cancer: Results from a Meta-cohort Analysis of 2411 Tumors. European Urol. 2019;75(3):423-32.

31. Deng N, Li L, Gao J, Zhou J, Wang Y, Wang C, Liu Y. Hsa_circ_0009910 promotes carcinogenesis by promoting the expression of miR449a target IL6R in osteosarcoma. Biochem Biophys Res Commun. 2018:495(1):189-96.

32. Li Y, Lin S, An N. Hsa_circ_0009910: oncogenic circular RNA targets microRNA-145 in ovarian cancer cells. Cell Cycle. 2020;19(15):1857-68.

33. Xiong $S$, Peng $H$, Ding $X$, Wang $X$, Wang L, Wu C, Wang S, Xu H, Liu Y. Circular RNA expression profiling and the potential role of hsa circ 0089172 in Hashimoto's thyroiditis via sponging miR125a-3p. Molecular Therapy Nucleic Acids. 2019;17:38-48.

34. Hansen TB, Jensen TI, Clausen BH, Bramsen JB, Finsen B, Damgaard CK, Kjems J. Natural RNA circles function as efficient microRNA sponges. Nature. 2013:495(7441):384-8.

35. Xing Q, Xie H, Zhu B, Sun Z, Huang Y. MiR-455-5p suppresses the progression of prostate cancer by targeting CCR5. BioMed Research Int. 2019;2019:6394784

36. Liu J, Zhang J, Li Y, Wang L, Sui B, Dai D. MiR-455-5p acts as a novel tumor suppressor in gastric cancer by down-regulating RAB18. Gene. 2016:592(2):308-15.

37. Godinez-Rubi M, Ortuno-Sahagun D. miR-615 Fine-Tunes Growth and Development and Has a Role in Cancer and in Neural Repair. Cells 2020 9(7).

38. Jia W, Xie L, Wang X, Zhang Q, Wei B, Li H, Qin S, Chen S, Liu J, Tan Y, et al. The impact of MCM6 on hepatocellular carcinoma in a Southern 
Chinese Zhuang population. Biomedicine Pharmacotherapy\&nbsp; 2020;127:110171.

39. Ju LL, Chen L, Li JH, Wang YF, Lu RJ, Bian ZL, Shao JG. Effect of NDC80 in human hepatocellular carcinoma. World J Gastroenterol. 2017;23(20):3675-83.

40. Ying $H, X u Z$, Chen M, Zhou S, Liang $X$, Cai X. Overexpression of Zwint predicts poor prognosis and promotes the proliferation of hepatocellular carcinoma by regulating cell-cycle-related proteins. Onco Targets\&nbsp; Therapy. 2018;11:689-702.

41. Lin SY, Pan HW, Liu SH, Jeng YM, Hu FC, Peng SY, Lai PL, Hsu HC. ASPM is a novel marker for vascular invasion, early recurrence, and poor prognosis of hepatocellular carcinoma. Clinical Cancer Res. 2008;14(15):4814-20.
42. Chen J, Xia H, Zhang X, Karthik S, Pratap SV, Ooi LL, Hong W, Hui KM. ECT2 regulates the Rho/ERK signalling axis to promote early recurrence in human hepatocellular carcinoma. J\&nbsp; Hepatol. 2015;62(6):1287-95.

43. Liao W, Liu W, Yuan Q, Liu X, Ou Y, He S, Yuan S, Qin L, Chen Q, Nong K, et al. Silencing of DLGAP5 by siRNA significantly inhibits the proliferation and invasion of hepatocellular carcinoma cells. PloS ONE. 2013;8(12):e80789.

\section{Publisher's note}

Springer Nature remains neutral with regard to jurisdictional claims in published maps and institutional affiliations.
Ready to submit your research? Choose BMC and benefit from:

- fast, convenient online submission

- thorough peer review by experienced researchers in your field

- rapid publication on acceptance

- support for research data, including large and complex data types

- gold Open Access which fosters wider collaboration and increased citations

- maximum visibility for your research: over 100M website views per year

At BMC, research is always in progress.

Learn more biomedcentral.com/submissions 